Article

\title{
Germany without Coercive Treatment in Psychiatry-A 15 Month Real World Experience
}

\author{
Martin Zinkler \\ Kliniken Lankreis Heidenheim gGmbH, Academic Teaching Hospital of Ulm University, Department of \\ Psychiatry, Psychotherapy and Psychosomatic Medicine, Schlosshaustr. 100, 89522 Heidenheim, Germany; \\ martin.zinkler@kliniken-heidenheim.de \\ Academic Editor: Anna Arstein-Kerslake \\ Received: 28 December 2015; Accepted: 14 March 2016; Published: 17 March 2016

\begin{abstract}
Coercive treatment with antipsychotic drugs was commonly used in German psychiatric institutions until it became a topic of substantial medical, legal and ethical controversy. In 2011 and 2012, several landmark decisions by Germany's Constitutional Court and Federal Supreme Court challenged this practice in all but life-threatening emergencies. In March 2013, the new legal provisions governing coercive treatment took effect allowing coercive medication under stricter criteria. While mainstream psychiatry in Germany resumed the use of coercive medication, although less frequently than before 2012, there are examples where clinicians put an even greater emphasis on consensual treatment and did not return to coercive treatment. Data from a case study in a local mental health service suggest that the use of coercive medication could be made obsolete.
\end{abstract}

Keywords: coercive treatment; human rights; psychiatry; Germany; constitutional court; UN convention

\section{Introduction}

Coercive use of antipsychotic medication is common in psychiatric institutions and usually affects people with severe mental illness [1,2]. Nevertheless, few studies into the rationale, frequency and effects of coercive medication have been conducted. While there is a remarkable absence of randomized trials on coercive antipsychotic treatment in hospitals, the use of community treatment orders has been studied in an experimental design in the UK and was found not to be effective in reducing relapse and readmission to hospital [3].

In 2011, Germany's Constitutional Court declared the regulations on coercive treatment in two German states (Rhineland-Palatine and Baden-Wurttemberg, 2 BvR 882/09 and 2 BvR 633/11) unlawful, which effectively stopped coercive antipsychotic treatment in these parts of Germany [4]. It was not the view of the Constitutional Court that coercive treatment per se was unconstitutional but rather that the criteria under which it could be given were far too wide. In 2012, Germany's Federal Supreme Court followed these rulings (XII ZB 99/12, XII ZB 130/12) [4] and extended the ban on coercive antipsychotic treatment across Germany, when it found the regulations governing coercive treatment in German guardianship law unconstitutional.

An outcry of protest, amongst others from Germany's professional association for psychiatry [5], led to changes in federal law allowing coercive treatment [6] under strict criteria (impaired capacity, prior attempts to reach consensual treatment, treatment is necessary to avert serious damage to the patient's health, least restrictive option, expected benefit exceeds the expected adverse effects).

Additional procedural safeguards were put in place, such as an assessment by a second opinion doctor and the option for the patient to go through an appeal process before treatment is commenced. In 2013, against fierce protest from users' organizations and a small minority within the psychiatric profession [4], these changes in guardianship law were passed by the German Bundestag. 
Between the decisions by Germany's Federal Supreme Court in June 2012 and the amendments in guardianship law passed by the Bundestag in January 2013 Germany was left without a law governing coercive treatment in psychiatry in all but life-threatening emergencies. The legal hiatus applied to both people with and people without capacity to consent to the treatment. Doctors were left with section 34 of Germany's criminal code, which allows action in justified emergencies (Rechtfertigender Notstand) to avert an imminent danger (similar to self-defense).

However, this section is not regarded as a justification for treatment of mental or other illness, and will only be used in exceptional circumstances, for example rapid tranquillization in a hospital emergency department, when the delay incurred to make a formal application and to call a judge would infer serious health risks.

The debate in public and in parliament [7] revealed an absence of data on the rationale, frequency, form and effect of coercive treatment in Germany's psychiatric hospitals. In small studies, coercive treatment is reported in $2 \%-8 \%$ of inpatients of psychiatric hospitals [8]. There is some data however, on the use of detention in hospitals and on the use of mechanical restraint (being strapped to a bed frame), physical restraint (being held down by staff), and seclusion (being locked in a small room). These vary considerably from hospital to hospital (between $2 \%$ and $10 \%$ of inpatients) [9] and between German states [10], suggesting perhaps that the use of coercion reflects the institutional culture rather than a variation in patient behavior for example between rural Bavaria and urban Hamburg.

At the same time on an international stage, combating human rights abuses in mental health care was identified as the "single most important priority for global mental health" ([11], p. 362). The 2015 first report of Germany by the UN Committee on the Rights of Persons with Disabilities [12] expressed serious concerns on Germany's compliance with the UN Convention and called on German authorities to acknowledge torture, inhuman and degrading treatment in psychiatric institutions and to end substitute decision making in German Guardianship proceedings.

Nevertheless, the legal void created by the court decisions did not prompt a huge interest in the research community to study this unique opportunity. Some observations were made and will be described in this paper.

\section{Methods}

A benchmark project [10] established in 1994 involves a network of psychiatric hospitals voluntarily submitting their data on the use of coercion in their institutions. These data will be reviewed against data on the use of coercive treatment in a group of hospitals in Bavaria since 2014 [13]. Furthermore, in an attempt to shed some light on institutional cultures some more detailed data will be presented from one institution with an uncommon approach to violence and coercion in mental health care. These data will highlight areas for further research and consideration of standard clinical practice.

In this paper a narrow definition of coercion is used. Included are: physical restraint (holding someone down), mechanical restraint (strapping someone to a bed frame), seclusion (locking someone in a room) and coercive medication (medication being administered against the declared will and/or with physical force).

\section{Results}

\subsection{Data on Coercion in Mental Health Institutions in Germany}

Prior to the Constitutional Court decisions of 2011, coercive medication could be administered to those patients being detained in psychiatric institutions under German mental health laws without an additional judicial procedure. As long as an individual was detained in hospital by a court of law, he or she could be treated against his or her will. The decision on involuntary medication was left to the treating physician.

Soon after the Constitutional Court rulings, some psychiatrists reported an increase in violence and other coercive measures in their hospitals as they felt unable to control their patients' disruptive 
behavior when these patients objected to treatment with antipsychotic medication. Flammer and Steinert looked at the network data and concluded that with the court rulings of 2011 and the ban on coercive antipsychotic medication, other forms of coercion were used more frequently in a defined group of patients, those with psychotic disorders, and presumably in situations where coercive medication was not permitted anymore [14]. They also reported significantly more violent incidents in patients with a diagnosis of psychosis ( $+44 \%)$.

Recently, data from a group of psychiatric institutions in Bavaria suggested that coercive medication under the new 2013 rules is used for $0.5 \%$ of inpatients [13]. This may well represent a less frequent use compared to pre-2011 data indicating coercive medication in $2 \%-8 \%$ of inpatients [8], as the new rules from 2013 introduced stricter criteria and additional safeguards regarding its use: a separate judicial procedure, a second opinion given by a doctor who is independent from the institution where the patient is detained and procedural requirements involving a separate court hearing.

\subsection{Data from Heidenheim Mental Health Service}

In a case study on a smaller level but over a longer time period, observations in a psychiatric department of a general hospital in South-West Germany allow for a more detailed narrative. The Heidenheim Department of Psychiatry serves a population of 130,000 in a small town and rural part of Baden-Wurttemberg. Against the mainstream of German psychiatry, coercive antipsychotic medication was not reintroduced with the new law in 2013, but remained obsolete since the 2011 court rulings.

Before 2011, coercive medication was used in 2-5 cases per year, thereby affecting up to $0.4 \%$ of inpatients. Compared to the data of the pre 2011 studies quoted above [8], this appears low and may well represent the therapeutic culture of this institution. The department, from its beginnings in 1995 operated an open-doors policy. There are no locked wards, voluntary and detained patients are being treated on open wards. All members of staff are trained in de-escalation, the department is a member of the above mentioned network of hospitals aiming to reduce coercion in mental health care. The department does not use seclusion rooms to contain disruptive behavior.

The hospital keeps detailed records of violent behavior of inpatients, of the use of coercion (according to the network definitions) and the use of antipsychotic medication. Violent incidents are defined as incidents where disruptive behavior by a patient leads to painful or harmful physical contact with another patient or member of staff (for example: when a cup is thrown and hits a wall, this is not a violent incident. If the cup hits a person, this will be counted. Threatening language is not counted; kicking, beating, pulling hair are counted).

For the data on antipsychotic medication, defined daily doses (DDDs) according to the WHO Collaborating Centre for Drug Statistics Methodology are used. This accounts for the different dose ranges of various antipsychotics. Some antipsychotics are used in a dose range between 2-12 mg, others between 100-900 mg. From the amount of each antipsychotic used within one year by a hospital department, defined daily doses can be calculated and added up. This allows a quantification of the use of medication of a certain group (antibiotics, antidepressants, antipsychotics, etc.) within a defined period.

Contrary to assumptions made by mainstream psychiatry and within the hospital network, the frequency of violent behavior (Table 1) and the frequency of other forms of coercion (mechanical restraint, Table 1) did not increase in Heidenheim once coercive use of antipsychotic medication was abandoned. During this period however, a shift in the therapeutic culture led to a reduction in the use of antipsychotic medication of more than $40 \%$ (Figure 1). 
Table 1. Violent incidents and mechanical restraint in Heidenheim Psychiatric Department 2009-2015.

\begin{tabular}{ccc}
\hline & Violent Incidents & $\begin{array}{c}\text { Percentage of Inpatients Subject } \\
\text { to Mechanical Restraint }\end{array}$ \\
\hline 2009 & 30 & 3.2 \\
2010 & 49 & 3.1 \\
2011 & 38 & 4.5 \\
2012 & 21 & 5.2 \\
2013 & 14 & 5.4 \\
2014 & 31 & 4.8 \\
2015 & 19 & 2.9 \\
\hline
\end{tabular}

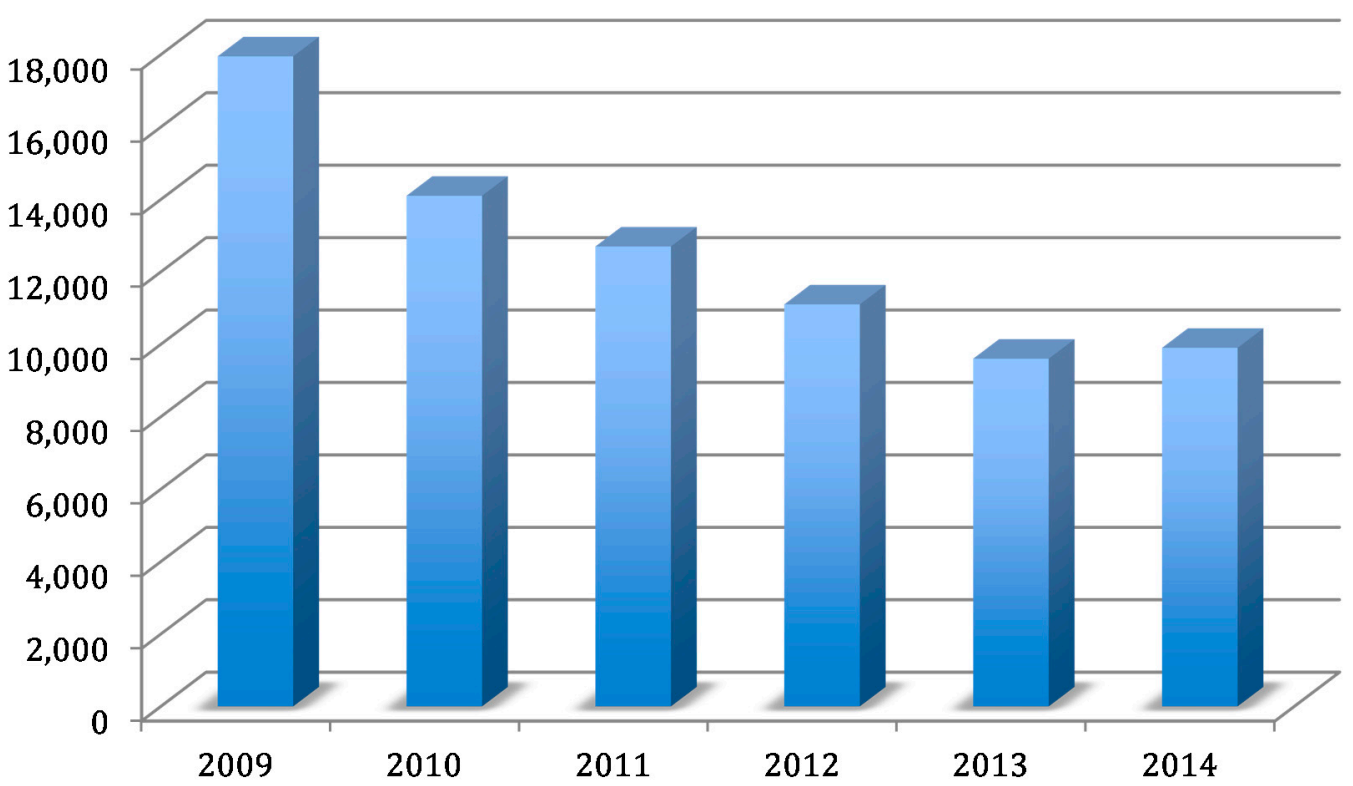

Figure 1. Defined Daily Doses of antipsychotic medication in Heidenheim Psychiatric Department 2009-2014.

It appears unlikely that these data result from a different mix of diagnoses treated in this hospital, as the population served by the institution, the number of inpatients (between 1250 and 1300 admissions per year) and the distribution of recorded diagnoses has largely remained the same during the period from 2009 to 2015.

\section{Conclusions}

Constitutional court rulings in Germany sparked a lively debate on the use of coercion in psychiatric institutions. Welcomed by users' organizations, the court rulings stipulated additional efforts in the field of human rights and mental health care. Germany's largest professional organization for psychiatry and psychotherapy responded with the formulation of an ethical position on autonomy and coercion in mental health care [15].

National and local data during the legal void between 2011 and 2013 and thereafter suggest that giving up coercive medication is not straightforward and problems arise when one form of coercive treatment (coercive medication) is stopped but other forms of coercion (restraint) and violence in psychiatric institutions increase. This was observed in several mental health services.

The data from one mental health service in south-west Germany go against this trend. In this service, giving up coercive medication did not coincide with an increase in another form of coercion (restraint or seclusion). Also, the service did not observe an increase in violent behavior and managed to reduce the use of antipsychotic medication substantially. On a cautious note, the data from a 
small-town/rural area may not be representative for mental health services in urban areas. Yet, the data cover a time period of several years and may well offer an opportunity to study complex interventions aimed at reducing coercion and violence in mental health care and to formulate best-practice models.

A further limitation to the research is that compulsory treatment was abolished, but compulsory detention was not. It may well be the case that while people were not legally coerced, they were well aware that if they wanted to get out, they would have to follow medical advice. Case reports about what happened in clinical situations without the option of coercive medication provide an insight into the institutional culture of this service [4].

From a human rights perspective, the German experience of the brief hiatus in the legal sanction of coercive medication from 2011 (in some parts of Germany, from June 2012 across Germany) to 2013 was largely disappointing. Little research was conducted until the new law was passed. There are however promising experiences, albeit on a small scale, which suggest that a reduction in the use of coercive treatment is possible under strict legal regulation.

An important barrier to accessing mental health services in high income countries is the stigma involved with mental illness and mental health services. Efforts to reduce stigma have been largely unsuccessful [16]. Stigma may be an obstacle in reporting human rights abuses ([11], p. 371). One might argue that reducing coercion in mental health services will help to reduce the stigma of mental illness and mental institutions. A mental health system treating everyone with care, dignity and respect would eventually earn respect from all corners of the community.

Conflicts of Interest: The author declares no conflict of interest.

\section{References}

1. Manuela Jarrett, Len Bowers, and Alan Simpson. "Coerced medication in psychiatric inpatient care: Literature review." Journal of Advanced Nursing 64 (2008): 538-48. [CrossRef] [PubMed]

2. Richard Bentall. "Too much coercion in mental health services." The Guardian, 1 February 2013. Available online: www.theguardian.com/commentisfree/2013/feb/01/mental-health-services-coercion (accessed on 5 December 2015).

3. Tom Burns, Jorun Rugkåsa, Andrew Molodynski, John Dawson, Ksenija Yeeles, Maria Vazquez-Montes, Merryn Voysey, Julia Sinclair, and Stefan Priebe. "Community treatment orders for patients with psychosis (OCTET): A randomised controlled trial." Lancet 381 (2013): 1627-33. [CrossRef]

4. Martin Zinkler, and Jose-Marie Koussemou. "Germany's Federal Constitutional Court rules against compulsory medication-Three case reports." Recht \& Psychiatrie 31 (2013): 76-79.

5. Deutsche Gesellschaft für Psychiatrie, Psychotherapie und Nervenheilkunde. "Stellungnahme zum Urteil des Bundesverfassungsgerichts vom 23.03.2011 zur Zwangsbehandlung im Maßregelvollzug 16.01.2012." Available online: www.dgppn.de/en/presse/stellungnahmen/detailansicht/article// zum-urteil-d-1.html (accessed on 5 December 2015).

6. $\quad$ Deutscher Bundestag. "17. Wahlperiode Drucksache 17/12086." Available online: http://dip21.bundestag. de/dip21/btd/17/120/1712086.pdf (accessed on 5 December 2015).

7. Deutscher Bundestag. "17. Wahlperiode Drucksache 17/12090." Available online: http:/ /dip21.bundestag. de/dip21/btd/17/120/1712090.pdf (accessed on 5 December 2015).

8. Tilman Steinert, and Thomas W. Kallert. "Involuntary medication in psychiatry." Psychiatrische Praxis 33 (2006): 160-69. [PubMed]

9. Tilman Steinert, Veronika Martin, Manfred Baur, Ulrich Bohnet, Rita Goebel, Gottfried Hermelink, Rita Kronstorfer, Wolfgang Kuster, Beate Martinez-Funk, Martin Roser, Albrecht Schwink, and Wolfram Voigtländer. "Diagnosis-related frequencies of compulsory measures in 10 German psychiatric hospitals and correlates with hospital characteristics." Social Psychiatry and Psychiatric Epidemiology 42 (2007): 140-45. [CrossRef] [PubMed]

10. Tilman Steinert, Martin Zinkler, Hans-Peter Elsässer-Gaißmaier, Axel Starrach, Sandra Hoppstock, and Erich Flammer. "Long-Term Tendencies in the Use of Seclusion and Restraint in Five Psychiatric Hospitals in Germany." Psychiatrische Praxis 42 (2015): 377-83. [PubMed] 
11. Vikram Patel, Arthur Kleinman, and Benedetto Saraceno. "Protecting the Human Rights of People with Mental Illness: A Call to Action for Global Mental Health." In Mental Health and Human Rights. Edited by Michael Dudley, Derrick Silove and Fran Gale. Oxford: Oxford University Press, 2012.

12. United Nations Committee on the Rights of Persons with Disabilities, Thirteenth Session. "Concluding observations on the initial report of Germany. UN document CRPD/C/DEU/CO/1." 25 March-17 April 2015. Available online: http://daccess-dds-ny.un.org/doc/UNDOC/GEN/G15/096/31/PDF/G1509631. pdf?OpenElement (accessed on 5 December 2015).

13. Margot Albus, Peter Brieger, and Wolfgang Schreiber. "Compulsory treatment with psychotropic drugs-Effects of the 2013 legislation amendment on treatment in psychiatric hospitals in Bavaria." Recht E Psychiatrie 33 (2015): 193-97.

14. Erich Flammer, and Tilman Steinert. “Impact of the Temporaneous Lack of Legal Basis for Involuntary Treatment on the Frequency of Aggressive Incidents, Seclusion and Restraint among Patients with Chronic Schizophrenic Disorders." Psychiatrische Praxis 42 (2015): 260-66. [PubMed]

15. Deutsche Gesellschaft für Psychiatrie, Psychotherapie und Nervenheilkunde. "Achtung der Selbstbestimmung und Anwendung von Zwang bei der Behandlung von psychisch erkrankten Menschen." Available online: www.dgppn.de/de/presse/stellungnahmen/detailansicht/article//achtung-der.html (accessed on 17 January 2016).

16. Michael Smith. "Anti-stigma campaigns: Time to change." The British Journal of Psychiatry 202 (2013): s49-50. [CrossRef] [PubMed]

(C) 2016 by the author; licensee MDPI, Basel, Switzerland. This article is an open access article distributed under the terms and conditions of the Creative Commons by Attribution (CC-BY) license (http://creativecommons.org/licenses/by/4.0/). 